\title{
A UNIÃO DA ALMA E DO INTELECTO NA FILOSOFIA DE PLOTINO
}

Bernardo G. S. L. Brandão* geraldosantos@yahoo.com.br

RESUMO Um dos aspectos mais importantes do sistema ético de Plotino é sua doutrina da união da alma e do Intelecto: essa união é o objetivo das práticas de purificação, o topo da prática dialética e a base da experiência mística. Mas, sendo inferior ao Intelecto, como é possível à alma alcançar essa união? Este artigo é uma tentativa de buscar a explicação plotiniana desse problema.

Palavras-chave Plotino; Alma; Intelecto; Experiência Mística.

ABSTRACT One of the most important features of Plotinus' ethical system is his doctrine of the union between soul and Intellect: this union is the goal of purification procedures, the summit of dialectic practice and the basis of mystical experience. But, being inferior to Intellect, how is it possible for the soul to achieve this union? This paper is an attempt at searching for the plotinian explanation for this problem.

Keywords Plotinus; Soul; Intellect; Mystical Experience.

Plotino afirma, em Enéada V, 1, que a Alma e, portanto, todas as almas são imagens do Intelecto, assim como a palavra proferida é imagem da 
palavra interior. Dessa maneira, por um lado, ela é uma realidade semelhante ao Intelecto e, por outro, inferior e derivada. É dotada de intelecção, mas a intelecção que lhe é própria é inferior, discursiva. ${ }^{1}$ Enquanto que, no Intelecto, todo o pensamento está presente ao mesmo tempo, a alma pensa uma coisa após a outra: num momento é Sócrates, em outro é um cavalo etc. ${ }^{2}$

Sendo uma entidade distinta e inferior, que pensa discursivamente, como a alma pode se unir tão estreitamente ao Intelecto, de modo a ser possível que chegue até mesmo a se tornar um intelecto? ${ }^{3}$

Para O'Daly, ${ }^{4}$ devemos nos lembrar, aqui, do axioma plotiniano, presente em V, 2, 2: cada ser está em identidade com seu antecessor enquanto mantém contato. ${ }^{5}$ Ou seja, o efeito não está separado da causa. Assim, a alma do vegetal morto volta para o lugar de onde veio, ou melhor, está sempre em seu princípio. Do mesmo modo, as fases superiores da alma estão umas nas outras até que o nível do Intelecto seja alcançado. Assim, a alma está presente no Intelecto de um modo virtual. Quando essa presença é atualizada, diz-se que a alma age como um intelecto.

O’Daly, também, apresenta uma passagem de III, $4,{ }^{6}$ em que Plotino declara que a alma é como um universo inteligível, ligada por suas partes superiores ao inteligível. Como a expressão "universo inteligível”, também, aparece em IV, 7, na passagem a respeito da união da alma com o Intelecto, e como o tratado III, 4 é o décimo quinto na cronologia de Porfírio, O’Daly encontra aqui uma boa evidência de que, desde o início de sua atividade literária, Plotino possuía uma concepção clara do "eu" original do homem, residente no Intelecto.

Pierre Hadot também tratou da questão em mais de um artigo. Em Les niveaux de conscience dans les états mystiques selon Plotin, ${ }^{7}$ ele diz que, segundo uma tradição platônica, à qual Plotino se liga, a alma possui diferentes partes que tendem a ser como que almas superpostas e constituem, por seu

1 V 1 1, 3. Isso não significa que seja o único tipo de intelecção que ela pode ter. Como veremos, quando a alma se volta para o Intelecto, ela pensa como um intelecto.

$2 \mathrm{~V}, 1,4,16-23$.

$3 \mathrm{VI}, 7,35,3-7 ; \mathrm{VI}, 9,3,22-24$. Quando intelecto e alma estão em minúsculas, trata-se dos intelectos e almas particulares. Quando estão em maiúsculas, das hipóstases Alma e Intelecto, bem como da Alma do mundo. Deve-se notar, no entanto, que, como as almas e a Alma do mundo participam da hipóstase Alma, e como os intelectos participam do Intelecto, na maior parte das vezes, o que se diz de um pode, de algum modo, dizer-se também do outro.

4 O'DALY, G. Plotinus's philosophy of the self. Shannon, 1973. p. 54.

$5 \mathrm{~V}, 2,2,3-4$.

6 III, 4, 3, 22. O'Daly, também, menciona III, 4, 6, 21-28, mas não vi em que essa passagem pode acrescentar algo ao argumento.

7 HADOT, P. Les niveaux de conscience dans les états mystiques selon Plotin. J ournal de Psychologie, n. 2-3, p. 246-247, 1980. 
agrupamento, a realidade humana. A parte inferior exerce as atividades da alma animal, ou seja, a sensação e o movimento, e da alma vegetativa, que é o crescimento. A central é a parte racional, que realiza seu discurso interior ou exterior no tempo. Por fim, distanciando-se dessa tradição platônica, Plotino afirmaria que existe uma parte superior da alma, que exerce a atividade do pensamento puro, típico do Intelecto. ${ }^{8}$ Essa seria a parte da alma mencionada em IV, $8,{ }^{9}$ que não desceu ao mundo sensível, permanecendo sempre no inteligível.

Para Hadot, isso acontece porque, na filosofia de Plotino, a alma seria, originalmente, uma das formas inteligíveis, um intelecto que se pensa no interior do Intelecto. Essa afirmação, diz ele, estaria ligada à questão da existência das formas dos indivíduos. Para ilustrar sua interpretação, Hadot cita o seguinte trecho da Enéada VI, 4:

E nós, o que somos nós? Somos aquele ou somos o que se associou e existe no tempo? Na verdade, antes de acontecer o nascimento, estávamos lá [no inteligível], sendo outros homens e, alguns, também deuses: almas puras e intelectos unidos à totalidade da essência, partes do inteligível, sem separação, sem divisão, mas sendo do todo (e nem mesmo agora estamos separados). Mas agora, daquele homem se aproximou outro homem, querendo ser. E nos encontrando, pois não estávamos separados do todo, ele se revestiu de nós e acrescentou a si mesmo aquele homem, o que cada um de nós era então. ${ }^{10}$

Segundo Hadot, essa passagem indicaria que a alma era antes um pensamento puro, ou seja, um intelecto particular dentro do Intelecto universal, que fazia parte do todo e participava da universalidade do Intelecto. A essa formapensamento transcendente ajuntou-se um outro homem, uma alma inferior, responsável pela individualização, localização e limitação do homem ligado a um corpo.

Em L'union de l'Ame avec l'Intellect divin dans l'expérience mystique plotinienne, ${ }^{11}$ Hadot desenvolve sua interpretação. Ele nota que, na filosofia de Plotino, cada forma, no interior do Intelecto, é uma essência viva e pensante, um intelecto particular que pensa todos os outros e que os contém potencialmente. Como o Intelecto é a totalidade das formas, cada uma delas é, por sua

8 Para um resumo das críticas neoplatônicas a essa doutrina de Plotino, ver: STEEL. The changing self, a study on the soul in later neoplatonism: lamblichus, Damascius and Priscianus. Bruxelas: Palais der Academien, 1978.

9 IV, 8, 8, 1-4.

$10 \mathrm{VI}, 4,14,16-25$.

11 COLLOQUE DE NEUCHÂTEL, 1985. Proclus et son influence. p. 3-27. 
vez, Intelecto total, de um modo potencial. ${ }^{12}$ Além disso, ainda que existam muitas almas - a Alma do mundo, as almas dos astros, as almas humanas -, de um certo modo, todas elas são uma só alma, coincidindo, por sua origem, com a essência da alma. ${ }^{13}$

A partir daí, mudando sua posição original, que indicava a forma do indivíduo como a parte superior da alma que estava no Intelecto, Hadot afirma que essa é a essência única da alma, comum a todas as almas, que é uma forma inteligível. Como as formas são, potencialmente, todo o Intelecto, é através da essência da alma que as almas estariam ligadas a ele.

Percebe-se que a idéia de O'Daly e a de Hadot são, basicamente, a mesma: a alma pode se tornar Intelecto porque, por sua parte superior, ela já é um intelecto. Assim, tudo o que se deve fazer é tomar consciência dessa situação, aquietando as partes inferiores e se concentrando na parte superior. ${ }^{14}$

Essa interpretação foi contestada por Blumenthal, ao afirmar ser possível que Plotino tenha passado a acreditar, no fim de sua carreira, que a parte mais elevada da alma exista apenas no nível da hipóstase Alma. ${ }^{15}$ Isso porque, para ele, é provável, ao menos na época dos últimos tratados, que Plotino não aceitasse a existência das formas dos indivíduos. Se fosse esse o caso, a parte da alma individual que não desceu não poderia estar no Intelecto. ${ }^{16}$

A questão da existência das formas dos indivíduos na filosofia de Plotino é controversa entre os estudiosos, o que reflete a ambigüidade dos próprios textos das Enéadas a esse respeito. Não creio, no entanto, que ela seja relevante para a determinação de onde a parte superior da alma está. Pois se, como defendem Hadot e O’Daly, está no Intelecto, ela pode ser tanto a forma do indivíduo quanto comum a todas as almas: as duas versões da interpretação de Hadot atestam isso.

O grande mérito da crítica de Blumenthal é ter chamado a atenção para o uso de noetón, inteligível, em Plotino: o termo pode tanto se referir ao Intelecto e às suas formas, quanto à Alma e às almas. Afinal, elas também são

12 A esse respeito, ver, por exemplo: $\mathrm{V}, 9,8,1-6$.

13 IV, 8, 3, 10-15.

14 Deve-se notar que, segundo Hadot, essa tomada de consciência da vida da alma superior não se faz pela consciência ordinária do homem, mas por uma supraconsciência. A esse respeito, ver: HADOT. Niveaux de conscience, p. 252-256.

15 BLUMENTHAL, H. On Soul and Intellect. In: The Cambridge companion to Plotinus. Cambridge: Cambridge University Press, 1996. p. 96.

16 BLUMENTHAL, H. Nous and Soul in Plotinus: some problems of demarcation. In: Atti del Convegno Internazionale sul tema: Plotino e il neoplatonismo in Oriente e in Occidente. Roma: 1970, p. 203-219. Não considerarei, aqui, a discussão que ele faz de uma passagem de $\mathrm{V}, 3$, nem outra sobre I, 1, pois não são conclusivas e, dessa forma, não favorecem nem desfavorecem o argumento. 
entidades imateriais e, portanto, inteligíveis. Em IV, 8, 7, ${ }^{17}$ Plotino diz que existem duas classes de natureza: a inteligível e a sensível; a alma, sendo intermediária entres essas realidades, está na fronteira do inteligível, mas, ainda assim, pertence à porção divina, ou seja, a imaterial. E no tratado formado pelas Enéadas VI, 4 e 5, o termo noetón é usado para se referir tanto ao Intelecto quanto à Alma.

Logo, os textos apresentados por O'Daly e Hadot não significam, necessariamente, que a alma esteja no Intelecto ${ }^{18}$ e que seja uma forma inteligível. Por conseqüência, a interpretação desses estudiosos passa a carecer de argumentos. É certo que eles têm o mérito de chamar a atenção para pontos importantes, como o axioma de $\mathrm{V}, 2$, segundo o qual cada ser está em identidade com seu sucessor enquanto mantém contato, bem como a relação estreita entre as formas inteligíveis e o Intelecto, e entre as almas e a Alma. No entanto, isso não é suficiente para dar sustentação às suas teses. De fato, através de uma análise um pouco mais cuidadosa, é possível perceber não apenas que a interpretação em questão não possui fundamento sólido nos textos das Enéadas, mas também que apresenta alguns problemas.

Em primeiro lugar, a compreensão de Hadot das duas passagens em que concentra sua argumentação (VI, 4, 14 e IV, 8, 8) não me parece satisfatória. Em VI, 4, 14, Plotino diz que, antes de encarnarmos em um corpo, estávamos no inteligível e éramos almas puras e intelectos. Ora, isso significa que estávamos no inteligível - não necessariamente no Intelecto - e que nossas almas estavam ligadas a intelectos, não que partes dessas almas eram intelectos. Não há, assim, nenhum fundamento para dizer que nossas almas eram formas inteligíveis.

Além disso, o outro homem, o que nasceu no tempo e que se ajuntou ao que éramos antes, não é uma alma inferior, mas o "composto animal", formado pelo corpo e por uma imagem da alma, "uma espécie de luz emitida"19 por ela, que informa e dá vida a esse corpo. ${ }^{20}$ Quando nasce esse composto, a alma

$17 \mathrm{Na}$ verdade, Blumenthal cita a passagem imediatamente anterior, IV, 8, 6, 23-28. Mas é em IV, 8,7 que a divisão das espécies de natureza em inteligível e sensível está mais claramente exposta.

$18 \mathrm{Em}$ várias passagens das Enéadas, é dito que a Alma e as almas estão no Intelecto, assim como o mundo sensível está na Alma e o Intelecto está no Um. Trata-se, aqui, de uma metáfora espacial indicando uma relação de dependência. Nesse sentido, é possível falar que toda a alma, incluindo sua parte superior, está no Intelecto. Mas isso não significa, como quer Hadot, que a parte superior da alma está no interior Intelecto, como uma forma inteligível.

$191,1,7,1-5$.

20 Sobre a ligação da imagem da alma com o corpo e a conseqüente formação do composto animal, bem como sobre a sua relação com a alma, ver: I, 1, 6-8. Sobre o desenvolvimento da doutrina da imagem da alma nos textos de Plotino, ver: IGAL. Aristóteles y la evolución de la antropología de Plotino. Pensamiento, v. 35, p. $315-346,1979$. 
dirige algumas de suas potências para ele e, dessa forma, liga-se ao mundo sensível, chegando a se esquecer do inteligível. Essa é a "perda das asas"21 da alma e sua descida ao corpo, ${ }^{22}$ que não deve ser compreendida espacialmente, mas como um dirigir-se de algumas potências da alma ao composto animal, àquilo que ela deu de si ao corpo:

É evidente que o que aqueles [os antigos] chamavam de "vir" deve significar que a natureza do corpo está ali e participa da vida e da alma. De modo algum o vir deve ser entendido localmente, mas como um modo desta comunhão, seja qual for. Assim, descer é vir a estar em um corpo (como dizemos que a alma está em um corpo), ou seja, dar a ele algo de si, não ser dele. ${ }^{23}$

Assim, em IV, 8, 8, ao falar de uma parte da alma que está sempre no inteligível, Plotino não quer dizer que sua parte superior está no Intelecto, nem que a parte inferior desceu ao sensível, mas simplesmente que, enquanto algumas potências da alma se dirigiram ao composto e ao mundo sensível, outras permaneceram ligadas ao inteligível.

O erro de base da interpretação de Hadot é compreender, literalmente, os trechos que falam de partes da alma. É certo que uma tradição filosófica que remonta à República e passa pelo Didascálico de Alcinoo afirma que a alma possui partes. É igualmente certo que Plotino é herdeiro dessa tradição - é por isso que, em vários momentos em que não tem necessidade de ser preciso, ele fala de partes da alma. Mas, como nota Blumenthal, ${ }^{24}$ parece que o modelo de alma utilizado nas investigações psicológicas mais profundas das Enéadas não é o da tripartição platônica, mas o aristotélico, da alma una que possui várias faculdades. Aliás, esse modelo é, expressamente, afirmado em mais de uma passagem: "Além disso, a alma é múltipla e também uma, mesmo não sendo composta de partes. Pois várias são suas potências", ${ }^{25}$ "Sendo a natureza da alma una, com uma multidão de potências...". ${ }^{26}$

Além disso, levando-se em conta certa passagem de V, 3, a interpretação de O'Daly e Hadot de que a parte superior da alma está no Intelecto não apenas se mostra improvável, mas parece mesmo ser incorreta:

21 IV , 8, 4, 23. Expressão retirada do Fedro 246c-d e 248c.

$22 \mathrm{VI}, 4,16,3-4$.

$23 \mathrm{VI}, 4,16,10-15$.

24 BLUMENTHAL. On Soul and Intellecte, de um modo mais detalhado, em Plotinus' psychology. The Hague: Martinus Nijhoff, 1971.

$25 \mathrm{Vl}, 9,1,39-40$.

$26 I I, 9,2,6$. 
- E o que impede de existir um intelecto puro na alma?

- Dizemos que nada.

- Mas, então, deve-se dizer que ele é da alma?

- Não dizemos que é da alma, mas dizemos que é nosso intelecto. Sendo diferente da parte discursiva e estando situado acima desta, contudo é nosso, mesmo se não o contarmos entre as partes da alma. Ou melhor, é nosso e não é nosso. Por isso nos valemos dele e não nos valemos, mas da razão discursiva valemo-nos sempre. É nosso quando o usamos e, quando não o usamos, não é nosso. ${ }^{27}$

Ou seja, a alma não tem um intelecto entre suas partes. Mas ele está acima dela e pode entrar em contato com ela em alguns momentos. Nesses momentos, podemos dizer que é nosso. Mas, se não existe um intelecto na alma, como se dá o contato entre os dois? A solução parece ser apontada em um texto de IV, 4, 2:

Com efeito, quando está naquele lugar [o inteligível], a alma alcança necessariamente a união com o Intelecto, já que para ele se voltou. Pois, para ele tendo-se voltado, não há nada entre eles. E, tendo ido para o Intelecto, harmoniza-se com ele; e, tendo-se harmonizado, une-se com ele, sem deixar de ser alma, mas sendo ambas as coisas, um e dois. ${ }^{28}$

Esse texto aparece em uma discussão sobre a existência ou inexistência da memória da vida terrena na alma que, com a morte, separou-se do corpo. Assim, a união de que se fala, aqui, parece ser a união que ocorre nessa situação. No entanto, em I, 2, Plotino diz ser possível sair do mundo sensível ainda em vida, através da virtude, ${ }^{29}$ e, por meio dela, após um processo de purificação do apego ao sensível, voltar-se para o Intelecto. Ainda, na Enéada $\mathrm{I}, 7,{ }^{30}$ ele afirma que a vida no corpo, por atrapalhar os atos próprios da alma - ou seja, a intelecção -, é um mal que pode terminar com a separação do corpo, realizada após a morte, mas também declara que, pela virtude, ainda em vida, a alma pode realizar essa separação. Assim, apesar de o contexto de IV, 4 ser o da alma separada do corpo após a morte, como essa separação é possível ainda em vida, o texto, também, vale para a compreensão de como a alma de um homem vivo pode se ligar ao Intelecto.

O que Plotino diz é que, quando a alma está no inteligível, ela está voltada para o Intelecto e harmonizada com ele. É como se a alma possuísse uma parte, ou, mais precisamente, alguma potência voltada para o sensível e outra

27 V , 3, 3, 21-29. (Tomei a liberdade de indicar em itálico as partes mais importantes da passagem para a presente discussão.)

$28 \mathrm{IV}, 4,2,25-29$.

$29 \mathrm{I}, 2,1,3$.

$301,7,3$. 
para o inteligível. Quando a potência que está voltada para o sensível está inativa, a alma pode voltar-se toda para o Intelecto. De fato, é o que ele dá a entender em II, 9:

Da nossa alma, uma parte está sempre voltada para coisas de lá [o mundo inteligível], outra para as coisas daqui [o mundo sensível] e outra no meio delas. Já que a natureza da alma é uma e nela há muitas potências, às vezes toda ela é transportada ao mais nobre de si mesma e do ser. Outras vezes, a parte pior, arrastada para baixo, arrasta consigo o meio. ${ }^{31}$

Esse texto declara que, quando a alma está no inteligível e voltada para o Intelecto, não há nada entre eles e ambos se unem, sendo, ao mesmo tempo, dois e um. Ora, dizer isso é equivalente a dizer, como em VI, 9, 3, que a alma tornou-se Intelecto.

Mas por que não existe nada entre a alma no inteligível e o Intelecto? Como é possível que, nesse caso, eles se unam? Em V, 1,22 Plotino afirma que não existe nada entre a alma e o Intelecto, exceto a alteridade. Ora, se a alma, quando está no inteligível, não tem nada que a separe do Intelecto, nesse caso, também não possui alteridade que a distinga. Embora Blumenthal, com relação a $\mathrm{V}, 1$, acredite que Plotino não ofereça nenhuma sugestão do que essa alteridade poderia ser, ${ }^{33}$ ela se torna clara a partir das presentes considerações: trata-se da associação da alma com o composto. ${ }^{34}$ Assim, uma alma se distinguiria de um intelecto por suas potências ligadas à imagem da alma e ao corpo, as quais a fazem viver a vida do composto, e seria semelhante a ele por sua potência voltada para a intelecção: "A alma possui uma parte voltada para o Intelecto, como que interior, e outra fora do Intelecto, voltada para o exterior. Por uma de suas partes é semelhante ao princípio de onde

31 II, 9, 2, 4-9. Essa doutrina é desenvolvida, por Plotino, de uma forma interessante: segundo ele, não temos consciência de tudo o que acontece em nossa alma. Como escreve Dodds, em Tradition and personal achievement in the philosophy of Plotinus, p. 5: "Plotino reconhece (antecipando Leibniz) que existem sensações que não alcançam a consciência, a menos que direcionemos a atenção especialmente para elas (IV, 4, 8; V, 1, 12), e, também (antecipando Freud), que existem desejos que permanecem na parte apetitiva e são desconhecidos por nós (IV, 8, 8, 9)". Para Dodds, essa atividade de exploração dos meandros da alma é o centro do plotinismo, onde estão suas descobertas mais originais. Plotino, diz ele, foi aparentemente o primeiro a fazer a distinção vital entre a personalidade total (psyché) e o euconsciência (hemeís). Não que exista, aqui, um conceito de inconsciente, semelhante ao de Freud. Para Plotino, a alma possui várias potências que estão ativas mesmo quando não temos consciência dessa atividade. Ora, tais potências podem ser irracionais, quando integram as partes inferiores da alma, mas podem ser supra-racionais, no caso da parte ligada ao inteligível.

$32 \mathrm{~V}, 1,3,21-22$.

33 BLUMENTHAL. Nous and Soul in Plotinus: some problems of demarcation, p. 207.

34 A Alma do mundo e algumas almas particulares, como as dos astros, apesar de governarem os corpos, não estão associadas a eles, mantendo-se impassíveis. Não é esse o caso da alma humana, que se associou e é afetada de tal modo pelos corpos que se pode dizer que uma parte dela desceu e recebeu a alteridade vinda do mundo sensível. 
vem, enquanto que, pela outra, ainda que sendo dessemelhante, é também ali semelhante". 35

Assim, a parte voltada para o Intelecto é a potência intelectiva da alma. A voltada para o exterior é a que se liga ao mundo sensível. Pela primeira, ela é semelhante ao Intelecto; pela outra, dessemelhante, ainda que também semelhante como uma imagem mais apagada ainda é semelhante ao seu modelo.

Seguindo esse raciocínio, é fácil concluir que, quando as potências da alma que a ligam ao sensível estão inativas, não há mais nada que a torne diferente de uma inteligência. É por isso que, em mais de uma ocasião, ${ }^{36}$ Plotino emprega a imagem do ouro impuro, misturado com outros elementos, que, ao ser purificado, se torna belo: também a alma ligada ao mundo sensível, purificada dessa ligação, volta-se toda para o inteligível e, tornando-se pura, assemelha-se ao Intelecto.

Pois bem, conforme a Enéada VI, 9, os seres imateriais não estão separados espacialmente, mas se distinguem pela diferença. Quando essa diferença é suprimida, não há mais nada que os separe. Assim, ocorrendo isso, eles se unem. ${ }^{37}$ Plotino alude a essa doutrina para explicar a união da alma com o Um, mas ela pode também ser aplicada à presente questão: quando é suprimido aquilo que tornava a alma diferente de um intelecto, ou seja, sua ligação com o sensível, não havendo mais como distingui-los, as almas passam a se comportar como intelectos e transformam-se em intelecto, embora sejam ainda almas, por terem a capacidade de voltar a se ligar ao sensível. Ora, como mostrou Hadot, os intelectos particulares contêm, potencialmente, o Intelecto universal e estão, intimamente, unidos a ele. Logo, quando a alma se torna semelhante a um intelecto, ela pode se unir ao Intelecto, sendo ambos duas e uma só entidade.

Assim, a alma que quer se unir ao Intelecto deve desligar as suas potências voltadas para o composto animal:

Aquele que vai conhecer o Intelecto, segundo parece, deve olhar a alma e sua parte mais divina. E talvez conseguirá isso desta forma: se retirar primeiro o corpo do homem, ou seja, de si mesmo, em seguida a alma que molda o corpo e, sobretudo, a sensação, os desejos, iras e as demais futilidades desse tipo, dada sua tendência tão pronunciada ao mortal. A parte restante é esta: a que dissemos ser imagem do Intelecto e que conserva certa luz daquele. ${ }^{38}$

$35 \mathrm{~V}, 3,7,26-28$.

36 I, 6, 50-54; IV, 7, 10, 47-55 e V, 8, 3, 11-15.

$37 \mathrm{VI}, 9,8,29-33$.

$38 \mathrm{~V}, 3,9,1-7$. 
Como se vê, a alma que molda o corpo não é outra senão a imagem da alma que, junto com o corpo, forma o composto. É ela que transmite os desejos corporais, as sensações, as iras e coisas desse tipo, perturbando a alma e impedindo-a de concentrar-se no Intelecto.

O que Plotino parece entender por "retirar", nessa passagem, é algo semelhante ao que ele compreende por "separação do corpo" em V, 1: não uma separação local, mas um desapego das imagens e alteridades que vêm do corpo. ${ }^{39}$ É um recolhimento das potências da alma que estão ligadas ao composto.

Para isso, em primeiro lugar, a razão não deve se apegar às paixões que surgem nas partes inferiores da alma, nem consentir nelas. ${ }^{40}$ Dessa forma, não ganham intensidade e, na medida do possível, a alma pode manter-se impassível. É por isso que Plotino diz que a alma deve buscar as sensações prazerosas, medicações e descansos apenas para não se perturbar, bem como deve evitar a dor, suportando-a com mansidão e não se deixando afetar por ela quando não for possível evitá-la. Ainda, deve também eliminar a ira e o temor ao máximo, não deixando que se espalhem, nem consentindo neles. Também, não buscará a comida e a bebida visando ao prazer, assim como os deleites venéreos. ${ }^{41}$

Depois, a alma aspirará a purificar, também, a sua parte irracional, de modo que não receba nenhum impacto exterior, isto é, das realidades sensíveis, ou, ao menos, buscará uma maneira de que esses impactos sejam escassos. Por fim, como o vizinho de um sábio que não se atreve a cometer atos reprováveis perto dele, tais impactos desvanecer-se-ão pela vizinhança da parte racional. Nesse estágio da purificação, não é apenas o que é moralmente errado que deve ser suprimido. Mesmo alguns atos que não sejam condenáveis devem ser evitados por conduzirem a uma ligação maior da alma com o corpo: "A meta não é estar isento do erro, mas ser deus". ${ }^{42}$

Quando a purificação é completada e a alma é capaz de realizar o recolhimento de suas potências ligadas ao composto, por alguns momentos - pois, em vida, isso só pode ocorrer em momentos definidos, e não de forma permanente, já que o corpo tem suas necessidades básicas que não podem e nem

$39 \mathrm{~V}, 1,10,24-27$.

40 Para toda essa passagem, a respeito de como a purificação deve ser realizada, ver: I, 2, 5.

41 Para JEVONS. Was Plotinus influenced by opium, algumas passagens da Vida de Porfírio sugerem que Plotino era um usuário de ópio. A mais importante delas, fundamental para o seu argumento, é um trecho do capítulo 8 (20-26), em que Porfírio fala que Plotino dormia e comia pouco. Ora, a leitura do trecho de I, 2, 5, aqui em discussão, mostra que tal atitude não é conseqüência de alguma substância química, mas uma opção ascética, aliás, bastante semelhante à de seguidores de outras tradições espirituais.

42 I, 2, 6, 2-3. 
devem, como, aliás, sinaliza o próprio Plotino, ${ }^{43}$ ser adiadas indefinidamente -, a alma repousa e cede sua atividade ao Intelecto. ${ }^{44}$ Quando isso ocorre, Plotino pode dizer que, por sua semelhança, a alma se tornou Intelecto ${ }^{45}$ e que, por sua quietude, ela está confiada e subordinada ao Intelecto. ${ }^{46}$

43 Em I, 9, Plotino posiciona-se contra a separação voluntária total da alma e do corpo, realizada com o suicídio. E, como vimos, ele diz, em I, 2, que a alma que vai purificar-se do sensível evita os prazeres e dores, mas, no entanto, deve procurar os descansos, medicações e sensações prazerosas que evitem perturbações maiores.

$44 \mathrm{~V}, 3,6,14-15$.

$45 \mathrm{VI}, 7,35,3-7$.

$46 \mathrm{VI}, 9,3,22-24$. 